\title{
Radiofrequency and Microwave Ablation in the Treatment of Hepatocellular Carcinoma
}

\author{
Ibrahim Halil Sever, ${ }^{1, *}$ Metin Sucu, ${ }^{1}$ and Erhan Biyiklii ${ }^{1}$ \\ ${ }^{1}$ Department of Radiology, Marmara University Medical Faculty, Istanbul, Turkey \\ "Corresponding author: Ibrahim Halil Sever, Department of Radiology, Marmara University Medical Faculty, Istanbul, Turkey. Tel: +90-5532040366, E-mail: \\ halilsever4022@hotmail.com \\ Received 2017 October 08; Revised 2018 April 17; Accepted 2018 April 24
}

\begin{abstract}
Background: Radiofrequency ablation (RFA) and microwave ablation (MWA) are the most common thermal ablation methods. Studies evaluating the effectiveness of these techniques have been carried out in recent years.

objectives: Evaluation of local therapeutic effectiveness of imaging guided percutaneous thermal ablation methods, short-middle term radiologic and clinical outcomes and to compare the effectiveness of treatment between two MWA and RFA methods.

Patients and Methods: We retrospectively browsed clinical-radiologic-pathologic-demographic parameters of patients who had undergone RF or MW treatment due to HCC between January 2012 and January 2015. Twelve females (30\%) and 28 males (70\%) who had at least 6 months follow-up were included. We evaluated the risk factors which we considered to affect the prognosis by means of Log-Rank (Mantel-Cox) analysis. Complications rates, ablative effectiveness, local progression free and disease free survival rates for 6 months and 1 year periods were calculated by Kaplan Meier test for each group separately. The results of two groups were compared by chi-square test.

Results: 6-month, 1-year and 2-year survival rates for thermal ablation were $84.6 \%, 78.7 \%$ and $65 \%$ for general; $76.3 \%, 55.2 \%, 33 \%$ for disease free and 78.9\%, 76.2\%, 37.3\% for local progression free respectively. Size and number of lesions were the only parameters that effective for all type of survival rates. In addition, Child-Pugh classification, AFP (alpha-fetoprotein) level and gender were found to affect just; general, disease free and local progression free survival rates respectively. No statistically significant difference was found in complication, ablative effectiveness, 6 month and 1 year general, disease free and progression free survival rates between RF and MW separately.

Conclusion: RF and MW ablation methods have similar complication rates, tumor ablation efficiency and survival rates for treatment in HCC patients.
\end{abstract}

Keywords: Hepatocellular carcinoma, Radiofrequency, Microwave, Ablation

\section{Background}

Hepatocellular carcinoma (HCC), a primary liver cancer, is the third most common cause of death due to cancer worldwide and the fifth most common cancer $(1,2)$. HCCs are usually in end stage when diagnosed and the 5year survival without treatment is under $5 \%$ (3). As surgery is the primary treatment method, imaging guided percutaneous tumor ablation could be considered as an alternative method for curative treatment in specially selected patient groups (4-6).

The most commonly used thermal ablation methods are radiofrequency ablation (RFA) and microwave ablation (MWA). These methods are based on the formation of coagulation necrosis by heat effect in tissues. RFA has been accepted as the most common thermal ablation method in the world because of $80-95 \%$ total tumor necrosis in early stage HCC and 5-year survival rates of 33-57\% (7). MWA therapy is a new technique that has many advantages, such as higher intratumoral temperature, improved heat release, optimal heating in cystic masses and a wider ablation volume compared to RFA technology widely used in the world $(8,9)$. Studies comparing these two thermal ablation methods in HCC treatment are carried out by various groups.

\section{Objectives}

In our study we aimed to get short-middle term radiologic and clinical outcomes and to compare the effectiveness of treatment between two MWA and RFA methods. 


\section{Patients and Methods}

\subsection{Case Selection and Patients}

Between January 2012 and January 2015, 40 patients; 12 females (30\%) and 28 males (70\%) who had at least 6 months of follow up were included. All procedures were in accordance with the ethical standards of the institutional and/or national research committee and with the 1964 Helsinki declaration and its later amendments or comparable ethical standards. Written informed consent was obtained from all patients before the procedure.

The mean age of the patients ranged from 42 to 79 years with a median age of 64 years. In 31 cases only one lesion, in seven cases, two lesions and in two cases three lesions were observed. The lesion diameters ranged from 8 to 49 $\mathrm{mm}$ (mean $25.8 \mathrm{~mm}$, median $25 \mathrm{~mm}$ ) ( $\leq 2 \mathrm{~cm}, \mathrm{n}=28 ; 2-3$ $\mathrm{cm}, \mathrm{n}=22 ; \geq 3 \mathrm{~cm}, \mathrm{n}=20$ )

In the first application, 51 lesions were ablated. In follow-ups, 19 lesions were ablated, three of which relapsed, 14 of which were recurrences and two of the remaining lesions were residual tumor tissue. Twelve of the cases had 2 sessions and three had 3 sessions of thermal ablation. The remaining 25 patients underwent single-seated thermal ablation. Of the 40 cases included in the study, 20 were RFA and 20 were MWA.

Patients who had adequate liver tissue remaining after ablation, lesions sized less than $5 \mathrm{~cm}$, maximum three lesions, and no non-hepatic metastatic lesions were included in the study. The lesions adjacent to the venous structures were operated, but lesions adjacent to the main bile ducts were not considered suitable for the procedure to prevent possible bile path damage. Twenty-five (62.5\%) of the cases were Child-Pugh stage A, eight (20\%) were Child-Pugh stage B, and seven (17.5\%) were Child-Pugh stage C. All of the ablation procedures were performed percutaneously.

\subsection{Technique}

In six patients whose lesions were not seen with ultrasonography (USG), the procedure was performed under CT guideline.

All interventional procedures were performed in the 'Interventional Radiology Unit' at a supine or supine oblique position relative to the localization of the lesion, under sedation applied by anesthesiologists, following routine surgical sterilization procedures, after 8 hours of fasting. Vital markers and oxygen saturation were monitored during the procedure. The procedures were performed by a single radiologist with 14 years of experience in interventional radiological procedures. All procedures were routinely performed under general anesthesia.

\section{3. $R F$}

For the RF ablation procedure, 'RITA Starburst Talon' (RITA Medical Systems, Angiodynamics Inc.) thermal ablation electrode and RITA model 1500X generator were used. Electrodes of $14 \mathrm{G}$ in diameter and $15 \mathrm{~cm}$ in length were preferred in our study (Figure 1). This electrode has 4 active needle electrodes and 1 active trocar.

This system is an infusion-based system that accelerates heat conduction. Because of the alternating current flow during RFA, pallets were attached to the front of both thighs for 'earthing' before the procedure.

After installation of the ablation electrode in a suitable position percutaneously through intercostal, subcostal or epigastric approach with imaging; needles that were inserted into the trocar opened to cover the lesion and adjacent parenchyma about $1 \mathrm{~cm}$ in diameter. Subsequently, the electrode was connected to the $150 \mathrm{~W}$ power generator and ablation started by setting the target temperature at $105^{\circ} \mathrm{C}$. During the process, the temperature was controlled by temperature gauges at the electrode tips, and the impedance was also checked on the chart on the generator. In this way, the process was more under control. During the process, the target temperature was reduced manually when necessary to prevent carbonization.

After the ablation was terminated, if the measured temperature was above $60^{\circ} \mathrm{C}$ for 30 seconds, the process was terminated but the ablation was continued for an additional 5 minutes if the control temperature was lower.

\section{4. $M W$}

For the MW ablation procedure, Acculis microwave tissue ablation system consisting of Accu2i pMTA applicator (Acculis MTA System, Angiodynamics Inc.), Sulis VpMTA Generator, optional MTA Temperature Probes, Acculis Local Control Station (LCS) was used. In our work we used a microwave generator with a power of $60-140$ W with $2.45 \mathrm{GHz}$ frequency and a microwave antenna with a thickness of 1.8 $\mathrm{mm}$ (approx. $15 \mathrm{G}$ ) and a length of $14 \mathrm{~cm}$ (Figure 2).

During the procedure, a sterile saline was used with a disposable pump to prevent overheating of the antenna frame and the cable that conducts microwave energy.

The microwave exit point (feed point) of the antenna was percutaneously located at the center of the lesion with intercostal, subcostal or epigastric approach. Generator power and ablation time were different for each patient and lesion and adjusted to the lowest power and time to cover the entire lesion, adhering to predetermined protocols of the equipment used.

In order for the ablation to be effective and safe, it was aimed to establish safe treatment limits by forming necrosis in $1 \mathrm{~cm}$ diameter peritumoral solid tissue. After 


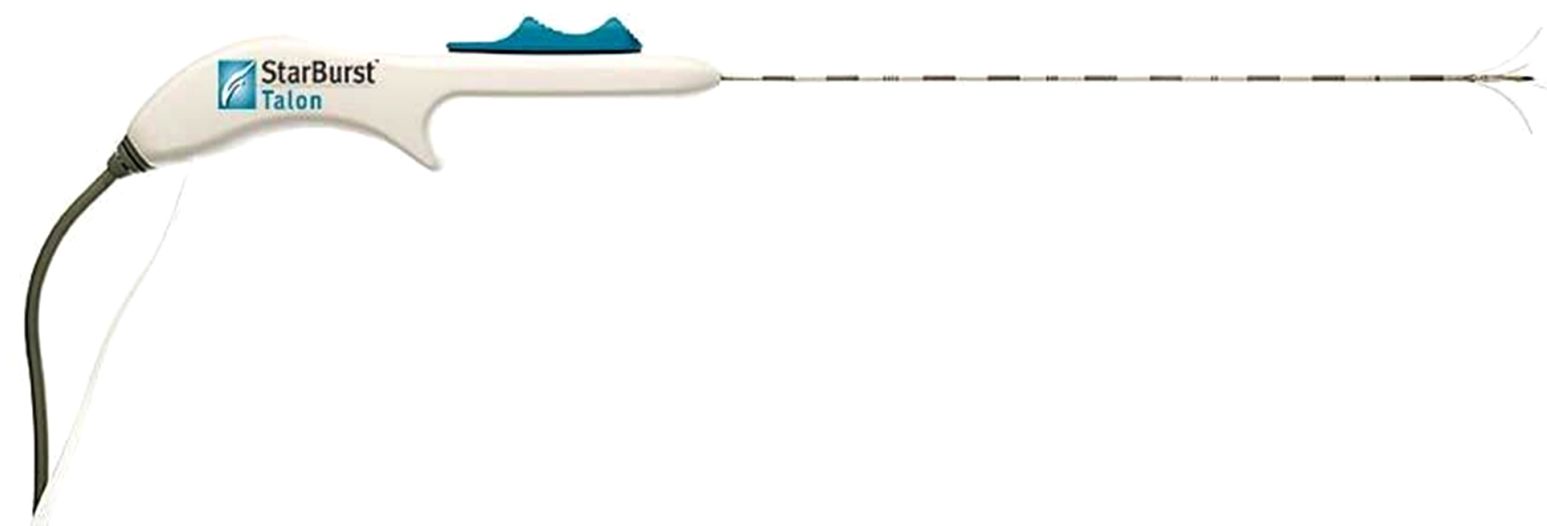

Figure 1. StarBurst Talon radiofrequency ablation (RFA) electrode.

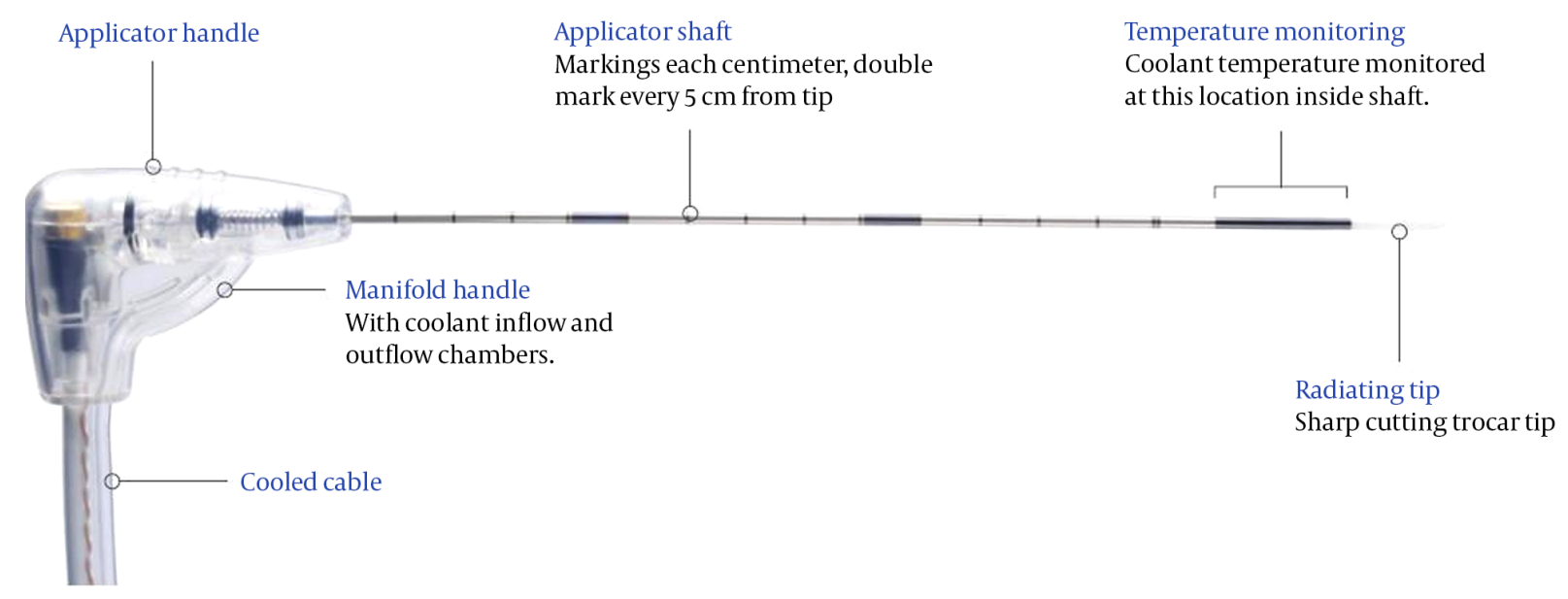

Figure 2. Accu2i pMTA microwave ablation (MWA) antenna.

completion of the ablation period, ablation was continued throughout the trocar tract to remove the risk of tumor eruption.

\subsection{Obtaining and Evaluating Images}

Follow-up of patients was performed by dynamic CT or MRI after one, three, and six months and afterwards in 6month intervals. Dynamic MR images were obtained using a 3.0 Tesla MR device (MAGNETOM Verio, Siemens Healthcare, Erlangen, Germany).

Dynamic MR images of arterial, portal and late phases were obtained. In addition, hepatobiliary phase images were taken routinely at 20 minutes to ensure optimal evaluation of the bile ducts.

Dynamic CT images were obtained using a 256-section multidetector CT scanner (SOMATOM Definition Flash, Siemens Healthcare, Erlangen, Germany). Parameters were standardized as 120 volts, $210 \mathrm{mAs}$, cross-sectional thickness $0.6 \mathrm{~mm}, 0.75$ pitch value, $128 \times 0.6 \mathrm{~mm}$ collimation.

Water-soluble non-ionic iodine contrast agents were applied intravenously with the aid of an automatic pump at a rate of $2 \mathrm{ml} / \mathrm{kg}$ for a speed of 3-5 ml / sec. The arterial phase images were taken 25 seconds after the contrast material started to be displayed, the portal phase images 
were taken after 60 seconds and the late phase images were taken after 110 seconds. Each phase was designed to last 6 seconds to provide acceptable soft tissue contrast.

Images were stored in 'Picture archiving and communication system' (PACS) and evaluated by two specialists using high resolution monitors (Tattoo 3 Megapixel Medical Monitor LCD), who were unaware of the details of the ablation procedure, different from the ablation procedure practitioner, and had 7 and 23 years of experience in abdominal radiology.

Full ablation criteria for CT and MRI were the absence of contrast enhancement around or within the tumor, the smoothness and sharpness of the ablation area boundaries, and the ablation area exceeding the previously determined tumor size. For MRI, apparent diffusion coefficient (ADC) values due to cell necrosis, loss of signal in T2weighted studies and no diffusion restriction in the diffusion sequence provided additional information in terms of full ablation. The recurrence criterion was defined as the detection of newly emerging arterial hypervascularity and lesions showing washout in the portal phase. Residue and relapse criteria were accepted as contrast enhancement in lesions that had to be treated and avascularized due to necrosis just after the treatment and follow-up, respectively.

In patients who develop post-procedural relapse, a new ablation procedure was planned if the current situation did not prevent ablation. Otherwise, the patient's treatment was regulated according to the decisions taken at the HCC board.

\subsection{Statistical Analysis of Data}

IBM SPSS statistics for Windows version 21.0 package program (2012) (Armonk, NY: IBM Corp) was used for statistical analysis.

Descriptive statistics were expressed as mean \pm standard deviation (minimum - maximum) or median for continuous variables, and categorical variables were expressed as number of cases and (\%).

The survival curves were calculated with the KaplanMeier analysis and compared with the Log-Rank test. The difference between the qualitative categorical variables was assessed by chi-square test. For continuous variables, the Student-t test was applied. Multivariate cox regression analysis was used to determine the factors that were effective on survival.

The results were evaluated at 95\% confidence interval, and the results below $\mathrm{P}<0.05$ were considered statistically significant.

\section{Results}

\subsection{Patient and Lesion Features}

Dynamic intravenous (IV) contrast enhanced abdominal CT or MRI one month after treatment showed residual tumoral tissue in three patients (7.5\%) and total ablation in 37 patients (92.5\%). Follow-up examinations in the 3rd month tumor relapse was detected in two patients (Figure 3A-D). One patient whose residual tumor tissue was detected died before the planned ablation procedure was performed. Ablations of the remaining patients were scheduled.

During the follow-up period, recurrent HCC lesions were observed in 14 patients. Two of these patients were unable to perform ablation procedure due to recurrence of more than three lesions in the liver, and two patients died before the planned ablation procedure. In the remaining 10 , ablation procedures were repeated. Residue tumor tissue was not observed in the examinations performed one month after the procedure. The third ablation procedure was planned for three patients of 10 , in whom recurrence was detected again on follow-up. No live tumor tissue was observed after third ablation procedures.

The parameters thought to be effective in the survival between these two groups were compared with chi square $\left(\mathrm{X}^{2}\right)$ test. There was no statistically significant difference between two groups of patients regarding age, gender, lesion size, AFP values, cirrhosis etiology, number of lesions and Child-Pugh class (Table 1).

In our study, there were seven Child-Pugh class $C$ patients (17.5\% of the total patients), while Child-Pugh $C$ patients were excluded from the study almost entirely in the literature. Mean survival times for overall survival were; 32,710 for Child A, 21,000 for Child B, and 15,333 months for Child C. Also mean survival times for Child A, B, and C patients were obtained. They were 20,406, 13,000 and 10,333 for disease free survival; and 21,590, 16,514 and 15,333 for local progression-free survival, respectively. The mean survival of Child $C$ class patients was lower than that of Child $A$ and $B$, but not statistically significant $(\mathrm{P}=0.080$ for overall, $\mathrm{P}=0.225$ disease-free and $\mathrm{P}=0.432$ for local progressionfree survivals).

\subsection{Complications and Side Effects}

One (2.5\%) patient was lost due to the ablation process. Pericardial effusion (thought to be due to anesthesia) was detected. The patient who was removed to the intensive care unit died after one day (Table 2).

In another patient with Child-Pugh A cirrhosis at 64 years of age, findings consistent with cholangitis and recurrent pneumothorax (Figure 4A and B) were found after the procedure, accepted as the major complication be- 

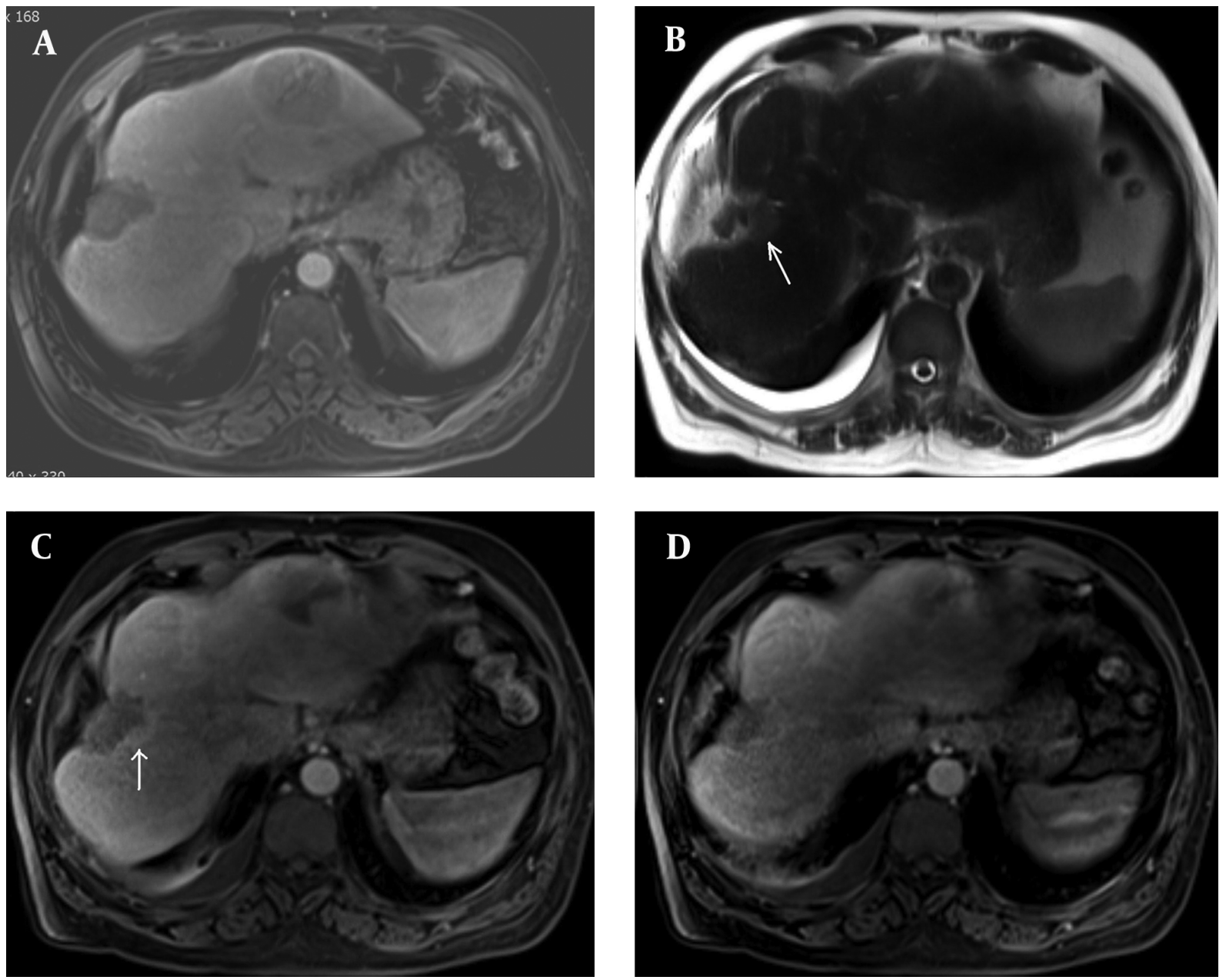

Figure 3. A 62-year-old male patient. A, Arterial phase MRI of the mass conforming to hepatocellular carcinoma (HCC) in the right lobe on the first month after microwave ablation (MWA). B, On the 3rd month follow-up, minimal hyperintense area on the edge of ablation area on axial T2W image. C, Again on the 3rd month follow-up arterial phase MRI showed early enhancement on the edge of the ablation zone and D, Portal phase MRI showed washout which was confirmed as relapse.

cause it caused changes in the patient's onset and treatment based on the standards of the international interventional radiology society.

In addition, four (10\%) patients had right hemithorax pleural effusion, one (2.5\%) patient developed subcapsular collection in the liver, two (5\%) patients had adjacent gastric wall thickening and one $(2.5 \%)$ patient had right portal vein thrombosis (Figure 5A). The patient who was diagnosed as thrombosis was treated with anticoagulant therapy (Figure 5B) and the other patients were treated conservatively. They were accepted as minor complications because the findings regressed.

Complication rates between RF ablation and MW ablation methods were compared. There was no significant difference between the two methods in terms of development of minor complication $\left(\mathrm{X}^{2}=1.580 ; \mathrm{P}=0.209>0.05\right)$ and ma- jor complication $\left(\mathrm{X}^{2}=0.017 ; \mathrm{P}=0.895>0.05\right)$.

\subsection{Follow-Up and Short-Mid Term Results}

The median follow-up was 12 months and ranged from 1 to 40 months. During follow-up, 14 of the patients were lost. The overall, disease-free and local progression-free survival rates were calculated with Kaplan-Meier analysis for 6 months, 1 year and 2 years separately (Figure 6). Local progression-free survival; was chosen as the predicted survival analysis which showed better efficacy of the ablation procedure than the disease-free survival, which included relapse and residual lesion but without recurrent lesion.

Overall survival rates for 6 months, 1 year and 2 years were $84.6 \%, 78.7 \%$ and $65 \%$, respectively. The mean overall survival time was 29.124 months. The mean duration of disease-free survival was 17.973 months. The 6-month 

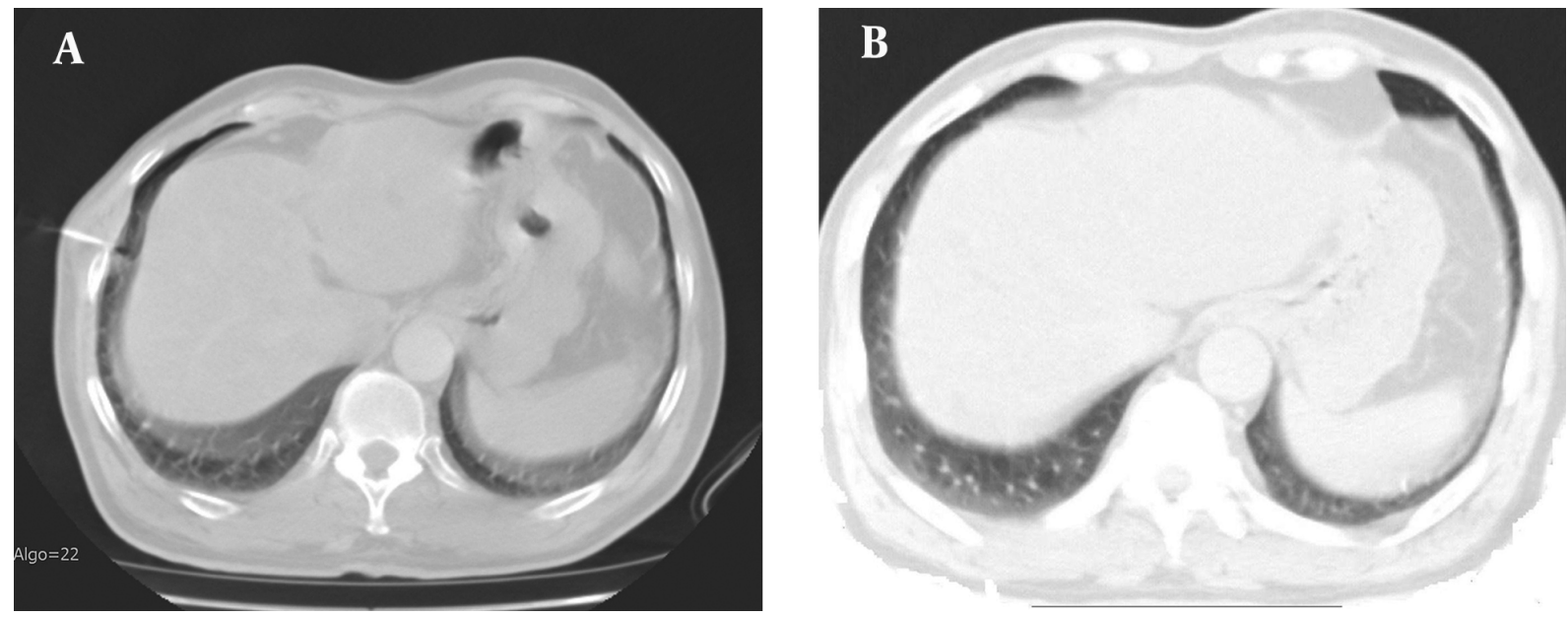

Figure 4. A 64-year-old man. CT-guided microwave ablation (MWA) was performed on the $16 \mathrm{~mm}$ in diameter lesion in the segment 7, compatible with hepatocellular carcinoma (HCC). A, Minimal pneumothorax developed during the procedure. B, Pneumothorax was completely regressive in the follow-up examination.
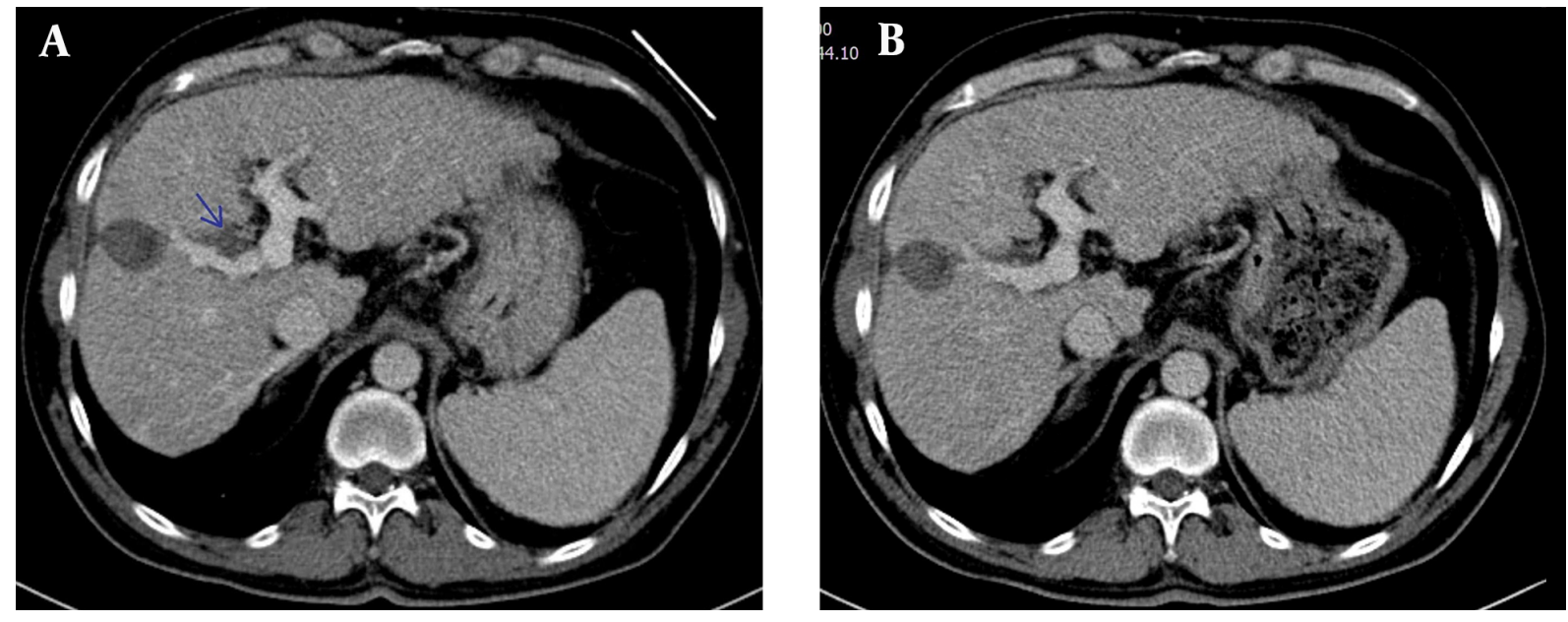

Figure 5. A 52-year-old male patient. Radiofrequency ablation (RFA) was applied to the the mass adjacent to the right lobe portal vein segmental branch. A, On the 2nd day, postoperative CT scan revealed partial thrombus in the right portal vein branch. B, In the 1 month follow-up examination, the portal thrombus appears to be regressive near totally.

disease-free survival rate was $76.3 \%$; the one-year diseasefree survival rate was $55.2 \%$ and the 2-year disease-free survival rate was $33 \%$. Local progression-free survival rates for 6 months, 1 year and 2 years were $78.9 \%, 76.2 \%$ and 37.3\% respectively. The mean overall survival time was 19.876 months.

Overall survival of patients with and without recurrent HCC lesions after treatment was calculated and compared with the Log Rank (Mantel-Cox) test. Estimated mean survival was calculated as 27.230 ( $\pm 3.257 \mathrm{SD}$ ) months in patients with recurrent lesion development and 28.664 ( \pm 3.642 SD) months in patients without recurrent lesion de- velopment. There was no statistically significant difference between the patients with and without recurrent lesions in terms of overall survival $(\mathrm{P}=0.253>0.05)$.

According to the size of the lesions, the cases were categorized as three groups, $\leq 2 \mathrm{~cm}, 2-3 \mathrm{~cm}$ and $\geq 3 \mathrm{~cm}$. The effect of lesion size on recurrence rate was searched and was not statistically significant $(P=0.249)$. Similarly, the effect of lesion size on complication rate was studied and it was not statistically significant. ( $\mathrm{P}=0.926$ for major and $\mathrm{P}=0.575$ for minor complication).

According to the cox regression model, the overall survival rate in patients with a lesion size of $\geq 3 \mathrm{~cm}$ was 13.7 


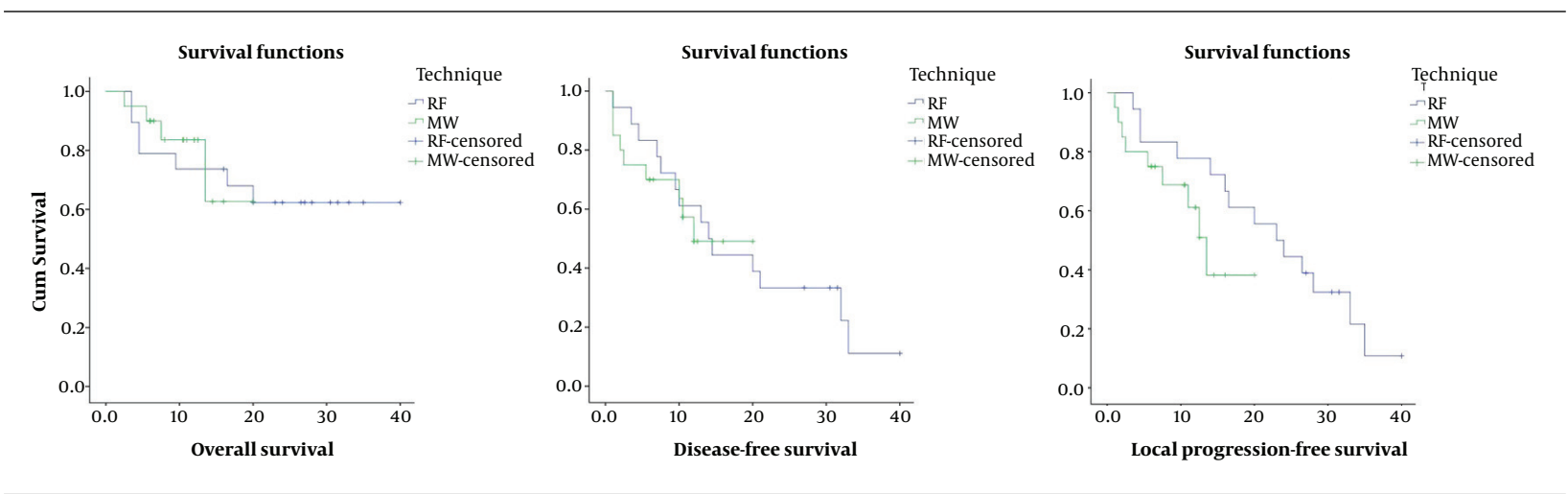

Figure 6. The overall, disease-free and local progression-free survival curves for radiofrequency (RF) and microwave (MW) ablation.

times lower. The effect of other risk factors was not significant for overall survival (Table 3). For disease-free and local progression-free survivals, gender was statistically significant for both. Other variables were not statistically significant.

\subsection{Comparison of RF and MW Ablation Methods}

In control dynamic scans performed one month after the procedure, full ablation was achieved in $92 \%$ of the RF ablation cases and $90 \%$ of the MW ablation cases, and the difference between these rates was not statistically significant according to the chi-square method $(\mathrm{P}=0.588)$.

Finally, overall survival, disease-free survival and local progression-free survival rates were compared for two groups with RF and MW ablation that had no differences in patient and lesion characteristics for 6 months and 1 year separately using the chi square $\left(\mathrm{X}^{2}\right)$ test

The overall survival rate in the RF group for 6-months and 1-year was 75\% and 70\%, respectively. In the MW group, the overall 6-month survival rate was 90\% and the 1-year overall survival rate was $69 \%$. The disease-free survival rate in the RF group for 6-months and 1-year were 75\% and 55\%, respectively. In the MW group, the disease-free 6-month and one-year survival rate was $65 \%$ and $54 \%$, respectively. In the RF group, the local progression-free survival rate for 6months and 1-year was 75\% and 70\%, respectively. In the MW group, the local progression-free 6-month survival rate was $75 \%$ and the one-year survival rate was $69 \%$.

No statistically significant difference was found between the overall, disease-free and local progression-free survival rates (Table 4 ).

\section{Discussion}

HCC is the third most common cause of cancer deaths worldwide and the fifth most common cancer (2). In a study conducted in our country, the etiologic factors for HCC were hepatitis B (44.4\%), hepatitis C (21.3\%), hepatitis B + D (5\%), alcohol (5.9\%) and cryptogenic cirrhosis (19.5\%) (10). The distribution of patients in our study is similar to this data, hepatitis B (50\%), hepatitis C (27.5\%), hepatitis B + D (5\%), alcohol (7.5\%) and cryptogenic cirrhosis (10\%).

Percutaneous ablation methods have emerged in recent years in the treatment of patients who cannot undergo surgical procedures. In one study, it was stated that percutaneous ablation methods had a higher costeffectiveness ratio with surgical approach (11). In the 1990s, percutaneous ethanol injection was the most commonly used method for this purpose. The inhomogeneous distribution of alcohol due to intratumoral septa and tumoral capsules; led to the search for minimally invasive different methods. Thermal ablation methods developed in recent years have taken place in many centers with ethanol ablation.

With today's developing technology, the efficiency of RF and MW ablation has increased. Several studies have reported that in small HCC lesions, thermal ablation methods provide tumor control and efficacy equivalent to surgical resection (12-15).

Another effect that emphasizes thermal ablation methods is that the proportion of effective tumor destruction is high, but the complication rate is lower than that of surgical treatment (16-19).

A number of publications comparing RF and MW ablation complication rates are available in the literature. In a study by Shibata and colleagues, the major complication rates of RF and MW ablation procedures were compared and there was no statistically significant difference between the two groups $(\mathrm{P}=0.36)(19)$. In another study involving 155 patients (78 RFA, 77 MWA) conducted by Zhang et al., pain, fever, asymptomatic pleural effusion and major complication rates were compared between both groups and no significant difference was observed (20). There- 
Table 1. Comparison of Predicted Parameters that May be Effective in the Survival of Patients Who Underwent Radiofrequency (RF) and Microwave (MW) Ablation Procedures $^{\mathrm{a}}$

\begin{tabular}{|c|c|c|c|}
\hline & $\mathbf{R F}$ & MW & Pvalue \\
\hline Mean age, $y$ & $64.3 \pm 8.99$ & $63.6 \pm 6.3$ & 0.780 \\
\hline Age & & & 0.736 \\
\hline$\leq 60$ & $6(30)$ & $7(35)$ & \\
\hline$>60$ & $14(70)$ & $13(65)$ & \\
\hline Gender & & & 0.129 \\
\hline Female & $8(40)$ & $4(20)$ & \\
\hline Male & $12(60)$ & $16(80)$ & \\
\hline Mean lesion size, $\mathrm{cm}$ & $2.4 \pm 1.1$ & $2.8 \pm 1.0$ & 0.161 \\
\hline Lesion size & & & 0.159 \\
\hline$\leq 2 \mathrm{~cm}$ & $11(44)$ & $6(20)$ & \\
\hline $2-3 \mathrm{~cm}$ & $7(28)$ & $12(40)$ & \\
\hline$\geq 3 \mathrm{~cm}$ & $7(28)$ & $12(40)$ & \\
\hline AFP & & & 0.723 \\
\hline $\mathrm{AFP}<15$ & $15(76)$ & $14(70)$ & \\
\hline $\mathrm{AFP} \geq 15$ & $5(24)$ & $6(30)$ & \\
\hline Etiology & & & 0.818 \\
\hline $\mathrm{HBV}$ & $11(55)$ & $9(45)$ & \\
\hline $\mathrm{HCV}$ & $5(25)$ & $6(30)$ & \\
\hline Other & $4(20)$ & $5(25)$ & \\
\hline Number of lesions & & & 0.582 \\
\hline 1 & $17(68)$ & $24(80)$ & \\
\hline 2 & $7(28)$ & $5(17)$ & \\
\hline 3 & $1(4)$ & $1(3)$ & \\
\hline Child-Pugh class & & & 0.439 \\
\hline A & $11(55)$ & $14(70)$ & \\
\hline B & $4(20)$ & $4(20)$ & \\
\hline $\mathrm{C}$ & $5(25)$ & $2(10)$ & \\
\hline
\end{tabular}

Abbreviations: AFP, alpha-feto protein; $\mathrm{X}^{2}$, chi-square test value; HBV, hepatitis $B$ virus; $\mathrm{HCV}$, hepatitis $\mathrm{C}$ virus; $\mathrm{MW}$, microwave; $\mathrm{RF}$, radiofrequency; $y$, year.

${ }^{\mathrm{a}}$ Values are expressed as No. (\%) or mean $\pm \mathrm{SD}$.

fore, in our study there was no significant difference in the minor complication development $\left(\mathrm{X}^{2}=1.580, \mathrm{P}=0.209>\right.$ $0.05)$ and major complication development $\left(\mathrm{X}^{2}=0.017 ; \mathrm{P}=\right.$ $0.895>0.05)$, compatible with the literature.

Surveillance studies related to percutaneous thermal ablation treatments have been studied many times in a number of centers. 1-, 3- and 5-year survival rates in small HCC lesions were obtained for MW ablation (83 - 96\%, 43 $73 \%$ and $33-70 \%$, respectively), and RF ablation (89-94\%, 62 - 68\% and $33-40 \%$, respectively) (21-25).

The ratios in our study were slightly less than those in

\begin{tabular}{|lc|}
\hline Table 2. Complication Distribution Secondary to Procedures & \\
\hline Complication & Number \\
\hline Major complications & 1 \\
\hline Cholangitis + pneumothorax & 1 \\
\hline Pericardial effusion ${ }^{\mathrm{a}}$ & \\
\hline Minor complications & 4 \\
\hline Pleural effusion & 1 \\
\hline Subcapsular hematoma & 1 \\
\hline Portal vein thrombosis & 2 \\
\hline Thickening of the stomach wall & \\
\hline
\end{tabular}

${ }^{a}$ Developed due to anesthesia.

the literature. The number of patients and patient selection criteria were considered to be effective in these outcomes. Child C class patients decreased our survival rates, but this was not statistically significant. The detection of acceptable survival rates in Child C class patients also suggested that thermal ablation methods can be used effectively in Child C class patients.

Two methods were used in the study of Shibata and colleagues in 72 patients (36 RF, $36 \mathrm{MW}$ ); treatment sessions per nodule, total ablation duration, and treatment efficacy were compared. The treatment session per nodule was less in RF ablation than in MW ablation and the ablation duration per session was less than MW ablation in comparison to RF ablation. There was no significant difference in therapeutic efficacy between these two methods. (96\% for RF and $89 \%$ for MW total ablation rate) (9). In a study involving 97 patients performed by Xu et al., treatment efficacy, recurrence rates and survival rates were compared and there was no significant difference between the two methods (26). Another study recently conducted by Zhang and his colleagues on 155 patients ( 78 RF, $77 \mathrm{MW}$ ), total ablation rates, relapse-recurrence rates and 1-, 3- and 5-year survival rates were compared. One-, 3- and 5-year disease-free survival rates were $70.5 \%, 42.3 \%$ and $34.2 \%$ for RF ablation and $62.3 \%, 33.8 \%$ and $20.8 \%$ for MW ablation respectively. RF ablation was found to be significantly better than MW ablation. No statistically significant difference was found in other components (20).

Risk factors were compared for both groups, no significant difference was found and two group features were assumed to be equivalent. In the two groups with similar characteristics, total ablation rate after RF ablation was 92\% and $90 \%$ for MW ablation, and there was no significant difference between the two methods in terms of efficacy of the technique. $(\mathrm{P}=0.588)$ In parallel with the literature, the overall, disease-free and local progression-free survival rates after 6-months and 1-year were compared be- 


\begin{tabular}{|c|c|c|c|c|c|c|c|c|c|c|c|c|c|c|c|}
\hline & \multicolumn{5}{|c|}{ Overall survival } & \multicolumn{5}{|c|}{ Disease-free survival } & \multicolumn{5}{|c|}{ Local progression-free survival } \\
\hline & \multirow[t]{2}{*}{ B } & \multirow[t]{2}{*}{ HR } & \multicolumn{2}{|c|}{ 95\% CI for HR } & \multirow{2}{*}{$\begin{array}{c}P \\
\text { value }\end{array}$} & \multirow[t]{2}{*}{ B } & \multirow[t]{2}{*}{ HR } & \multicolumn{2}{|c|}{ 95\% CI for HR } & \multirow{2}{*}{$\begin{array}{c}P \\
\text { value }\end{array}$} & \multirow[t]{2}{*}{ B } & \multirow[t]{2}{*}{ HR } & \multicolumn{2}{|c|}{ 95\% CI for HR } & \multirow{2}{*}{$\begin{array}{c}P \\
\text { value }\end{array}$} \\
\hline & & & Lower & Upper & & & & Lower & Upper & & & & Lower & Upper & \\
\hline Technique & -0.874 & 0.417 & 0.064 & 2.720 & 0.361 & 0.039 & 1.040 & 0.309 & 3.494 & 0.950 & 0.694 & 2.002 & 0.501 & 8.001 & 0.326 \\
\hline Gender & 1.423 & 4.148 & 0.419 & 41.097 & 0.224 & 1.525 & 4.594 & 1.137 & 18.564 & 0.032 & 1.596 & 4.934 & 1.201 & 20.266 & 0.027 \\
\hline \multicolumn{16}{|l|}{ Etiology } \\
\hline HBV & & & & & 0.338 & & & & & 0.953 & & & & & 0.737 \\
\hline $\mathrm{HCV}$ & -0.418 & 0.659 & 0.046 & 9.473 & 0.759 & 0.122 & 1.130 & 0.333 & 3.839 & 0.845 & -0.348 & 0.706 & 0.182 & 2.742 & 0.615 \\
\hline Other & 1.005 & 2.733 & 0.479 & 15.600 & 0.258 & 0.179 & 1.196 & 0.370 & 3.862 & 0.765 & 0.177 & 1.193 & 0.364 & 3.906 & 0.771 \\
\hline \multicolumn{16}{|l|}{ AFP value } \\
\hline$\leq 15,>15$ & -0.427 & 0.652 & 0.082 & 5.201 & 0.687 & 0.819 & 2.268 & 0.725 & 7.095 & 0.159 & 0.560 & 1.751 & 0.536 & 5.726 & 0.354 \\
\hline \multicolumn{16}{|l|}{$\begin{array}{l}\text { Number of } \\
\text { lesions }\end{array}$} \\
\hline$<3, \geq 3$ & 0.148 & 1.159 & 0.206 & 6.528 & 0.867 & -0.794 & 0.452 & 0.138 & 1.485 & 0.191 & -0.623 & 0.536 & 0.153 & 1.874 & 0.329 \\
\hline \multicolumn{16}{|l|}{$\begin{array}{l}\text { Child-Pugh } \\
\text { class }\end{array}$} \\
\hline A & & & & & 0.844 & & & & & 0.695 & & & & & 0.835 \\
\hline B & -0.112 & 0.894 & 0.090 & 8.882 & 0.924 & 0.413 & 1.511 & 0.365 & 6.255 & 0.569 & 0.450 & 1.568 & 0.346 & 7.098 & 0.559 \\
\hline C & 0.406 & 1.501 & 0.225 & 10.015 & 0.675 & 0.653 & 1.922 & 0.405 & 9.130 & 0.411 & 0.106 & 1.111 & 0.232 & 5.324 & 0.895 \\
\hline \multicolumn{16}{|l|}{ Lesion size } \\
\hline$\geq 3,<3$ & 2.621 & 13.749 & 1.021 & 185.145 & 0.048 & 0.070 & 1.072 & 0.234 & 4.903 & 0.929 & 0.536 & 1.709 & 0.331 & 8.823 & 0.522 \\
\hline
\end{tabular}

Abbreviations: AFP, alpha-feto protein; B, beta coefficient; CI, confident interval; HBV, hepatitis B virus; HCV, hepatitis C virus; HR, hazard ratio.

\begin{tabular}{|c|c|c|c|c|}
\hline & \multirow[t]{2}{*}{$\mathbf{R F}$} & \multirow[t]{2}{*}{ MW } & \multicolumn{2}{|c|}{ Test Statistics } \\
\hline & & & $\mathrm{X}^{2}$ & P value \\
\hline Local progression-free 6-month & & & - & - \\
\hline 0 & $5(25)$ & $5(25)$ & & \\
\hline 1 & $15(75)$ & $15(75)$ & & \\
\hline Local progression-free 1-year & & & 0.00221 & 0.963 \\
\hline 0 & $6(30)$ & $4(31)$ & & \\
\hline 1 & $14(70)$ & $9(69)$ & & \\
\hline Overall 6-month & & & 1.55844 & 0.212 \\
\hline 0 & $5(25)$ & $2(10)$ & & \\
\hline 1 & $15(75)$ & $18(90)$ & & \\
\hline Overall 1-year & & & 0.00221 & 0.963 \\
\hline 0 & $6(30)$ & $4(31)$ & & \\
\hline 1 & $14(70)$ & $9(69)$ & & \\
\hline Disease-free 6-month & & & 0.47619 & 0.490 \\
\hline 0 & $5(25)$ & $7(35)$ & & \\
\hline 1 & $15(75)$ & $13(65)$ & & \\
\hline Disease-free 1-year & & & 0.00423 & 0.948 \\
\hline 0 & $9(45)$ & $6(46)$ & & \\
\hline 1 & $11(55)$ & $7(54)$ & & \\
\hline
\end{tabular}

Abbreviations: MW, microwave; $\mathrm{n}$, number; $\mathrm{RF}$, radiofrequency; $\mathrm{X}^{2}$, chi-square test value.

${ }^{\mathrm{a}}$ Values are expressed as No. (\%).

tween RF ablation and MW ablation methods, and no statistically significant difference was found $(P>0.005)$.

According to the cox regression, similar to some previous studies, we found that the lesion size affected the overall survival. However, it had no effect on the other survival rates. For us this may depend on the success rate of the ablative efficiency of devices that we used.

Additionally, only gender was found statistically significant for disease-free and local progression-free survival. We think that this is related to our patient count and an it 
is insignificant finding.

There have been limitations in our study. The number of patients was found to be less than the studies in the literature and the relatively short duration of follow-up have been identified as the most important limitations. In addition, additional manipulations to achieve total ablation per session and the total time spent per session for RFA and MWA were not compared. Finally, studies similar to that in the literature, a single RF ablation electrode type and MW ablation antenna were compared. It was thought that this could lead to incomplete information in comparing the technical and technological characteristics of the two methods.

In conclusion, similar complication rates, tumoral ablative efficacy and survival rates were observed between percutaneous RF and MW ablation methods and there was no statistically significant difference between the two methods. Because of the use of electrodes and antennas for both methods, these results cannot be generalized for RF and MW ablation technology. However, the systems we used in our study and the results we found provide additional information on other studies and are also helpful in using the right method.

\section{Footnotes}

Authors' Contributions: Study conception and design: Ibrahim Halil Sever and Erhan Biyikli; acquisition of data: Ibrahim Halil Sever and Metin Sucu; analysis and interpretation of data: Ibrahim Halil Sever and Erhan Biyikli; drafting of manuscript: Ibrahim Halil Sever; critical revision: Ibrahim Halil Sever, Erhan Biyikli and Metin Sucu; final approval of the version to be published: Ibrahim Halil Sever, Erhan Biyikli and Metin Sucu.

Financial Disclosure: None declared.

Funding/Support: None declared.

\section{References}

1. Parkin DM. Global cancer statistics in the year 2000. Lancet Oncol. 2001;2(9):533-43. doi: 10.1016/s1470-2045(01)00486-7.

2. World Health Organization. Mortality Database. WHO Statistical Information System; 2008. Available from: http://www.who.int/whosis.

3. Clark HP, Carson WF, Kavanagh PV, Ho CP, Shen P, Zagoria RJ. Staging and current treatment of hepatocellular carcinoma. Radiographics. 2005;25 Suppl 1:S3-23. doi: 10.1148/rg.25si055507. [PubMed: 16227495].

4. Llovet JM, Burroughs A, Bruix J. Hepatocellular carcinoma. Lancet. 2003;362(9399):1907-17. doi: 10.1016/s0140-6736(03)14964-1.

5. Llovet JM, Bruix J. Novel advancements in the management of hepatocellular carcinoma in 2008. J Hepatol. 2008;48 Suppl 1:S20-37. doi: 10.1016/j.jhep.2008.01.022. [PubMed: 18304676].

6. Bruix J, Sherman M, Practice Guidelines Committee AAFTSOLD. Management of hepatocellular carcinoma. Hepatology. 2005;42(5):120836. doi: 10.1002/hep.20933. [PubMed: 16250051].
7. Qian GJ, Wang N, Shen Q, Sheng YH, Zhao JQ, Kuang M, et al. Efficacy of microwave versus radiofrequency ablation for treatment of small hepatocellular carcinoma: experimental and clinical studies. Eur Radiol. 2012;22(9):1983-90. doi: 10.1007/s00330-012-2442-1. [PubMed: 22544225].

8. Martin RC, Scoggins CR, McMasters KM. Microwave hepatic ablation: initial experience of safety and efficacy.J Surg Oncol.2007;96(6):481-6. doi: 10.1002/jso.20750. [PubMed: 17654527].

9. Shibata T, Iimuro Y, Yamamoto Y, Maetani Y, Ametani F, Itoh K, et al. Small hepatocellular carcinoma: comparison of radio-frequency ablation and percutaneous microwave coagulation therapy. Radiology. 2002;223(2):331-7. doi: 10.1148/radiol.2232010775. [PubMed: 11997534].

10. Alacacioglu A, Somali I, Simsek I, Astarcioglu I, Ozkan M, Camci C, et al. Epidemiology and survival of hepatocellular carcinoma in Turkey: outcome of multicenter study. Jpn J Clin Oncol. 2008;38(10):683-8. doi: 10.1093/jjco/hyn082. [PubMed: 18753360].

11. Llovet JM, Mas X, Aponte JJ, Fuster J, Navasa M, Christensen E, et al Cost effectiveness of adjuvant therapy for hepatocellular carcinoma during the waiting list for liver transplantation. Gut.2002;50(1):123-8. doi: 10.1136/gut.50.1.123.

12. Curley SA. Radiofrequency ablation leads to excellent local tumor control and durable longterm survival in specific subsets of early stage HCC patients confirming to the Milan criteria. Ann Surg. 2010;252(6):913-4. doi: 10.1097/SLA.0b013e3182034862. [PubMed: 21107101]

13. Minami Y, Kudo M. Radiofrequency ablation of hepatocellular carcinoma: Current status. World J Radiol. 2010;2(11):417-24. doi: 10.4329/wjr.v2.i11.417. [PubMed: 21179308]. [PubMed Central: PMC3006479].

14. Chen MS, Li JQ, Zheng Y, Guo RP, Liang HH, Zhang YQ, et al. A prospective randomized trial comparing percutaneous local ablative therapy and partial hepatectomy for small hepatocellular carcinoma. Ann Surg. 2006;243(3):321-8. doi: 10.1097/01.sla.0000201480.65519.b8. [PubMed: 16495695]. [PubMed Central: PMC1448947].

15. Wang ZL, Liang P, Dong BW, Yu XL, Yu DJ. Prognostic Factors and Recurrence of Small Hepatocellular Carcinoma after Hepatic Resection or Microwave Ablation: A Retrospective Study. J Gastrointest Surg. 2007;12(2):327-37. doi:10.1007/s11605-007-0310-0.

16. Guglielmi A, Ruzzenente A, Valdegamberi A, Pachera S, Campagnaro T, D'Onofrio M, et al. Radiofrequency ablation versus surgical resection for the treatment of hepatocellular carcinoma in cirrhosis.J Gastrointest Surg. 2008;12(1):192-8. doi: 10.1007/s11605-007-0392-8. [PubMed: 17999123].

17. Hiraoka A, Horiike N, Yamashita Y, Koizumi Y, Doi K, Yamamoto Y, et al. Efficacy of radiofrequency ablation therapy compared to surgical resection in 164 patients in Japan with single hepatocellular carcinoma smaller than $3 \mathrm{~cm}$, along with report of complications. Hepatogastroenterology. 2008;55(88):2171-4. [PubMed: 19260499].

18. Guo WX, Sun JX, Cheng YQ, Shi J, Li N, Xue J, et al. Percutaneous radiofrequency ablation versus partial hepatectomy for small centrally located hepatocellular carcinoma. World J Surg. 2013;37(3):602-7. doi: 10.1007/s00268-012-1870-z. [PubMed: 23212793].

19. Huang J, Yan L, Cheng Z, Wu H, Du L, Wang J, et al. A randomized trial comparing radiofrequency ablation and surgical resection for HCC conforming to the Milan criteria. Ann Surg. 2010;252(6):903-12. doi: 10.1097/SLA.ob013e3181efc656. [PubMed: 21107100].

20. Zhang Z, Zhang L, Wang N, Shen Q, Cheng W, Qian G. Therapeutic Efficacy of Percutaneous Radiofrequency Ablation versus Microwave Ablation for Hepatocellular Carcinoma. PLoS ONE. 2013;8(10). e76119. doi: 10.1371/journal.pone.0076119.

21. Lu MD, Chen JW, Xie XY, Liu L, Huang XQ, Liang LJ, et al. Hepatocellular carcinoma: US-guided percutaneous microwave coagulation therapy. Radiology. 2001;221(1):167-72. doi: 10.1148/radiol.2211001783. [PubMed: 11568335]. 
22. Dong B, Liang P, Yu X, Su L, Yu D, Cheng Z, et al. Percutaneous sonographically guided microwave coagulation therapy for hepatocellular carcinoma: results in 234 patients. AJR Am J Roentgenol. 2003;180(6):1547-55. doi: 10.2214/ajr.180.6.1801547. [PubMed: 12760916].

23. Beppu T, Ogawa M, Matsuda T, Ohara C, Hirota M, Shimada S, et al. [Efficacy of microwave coagulation therapy (MCT) in patients with liver tumors]. Gan To Kagaku Ryoho. 1998;25(9):1358-61. [PubMed: 9703828].

24. Buscarini L, Buscarini E, Di Stasi M, Vallisa D, Quaretti P, Rocca A. Percutaneous radiofrequency ablation of small hepatocellular carcinoma: long-term results. Eur Radiol. 2001;11(6):914-21. doi: 10.1007/s003300000659. [PubMed: 11419162].

25. Poon RT, Fan ST, Tsang FH, Wong J. Locoregional therapies for hepatocellular carcinoma: a critical review from the surgeon's perspective. Ann Surg. 2002;235(4):466-86. [PubMed: 11923602]. [PubMed Central: PMC1422461].

26. Xu HX, Xie XY, Lu MD, Chen JW, Yin XY, Xu ZF, et al. Ultrasound-guided percutaneous thermal ablation of hepatocellular carcinoma using microwave and radiofrequency ablation. Clin Radiol.2004;59(1):53-61. [PubMed:14697375]. 